\title{
GROWTH TEMPERATURES, VIRULENCE, SURVIVAL, AND NUTRITION OF LEPTOSPIRES*
}

\author{
H. C. Ellinghausen, $\mathbf{J}_{\mathbf{R}}$ \\ National Animal Disease Laboratory, Agricultural Research Service, \\ U.S. Department of Agriculture, Ames, Iowa 50010, U.S.A.
}

THE effect of elevated temperatures upon leptospiral growth in vitro is poorly understood. Replication of leptospires in many animal hosts probably takes place at $37^{\circ} \mathrm{C}$ or higher, yet efficient laboratory propagation demands incubation at $29-30^{\circ} \mathrm{C}$. In some instances short initial periods of incubation at $37^{\circ} \mathrm{C}$ have been thought to favour isolation. A gap in our knowledge exists as to exact temperatures within host tissues and the substances in blood, brain, liver, and kidney that may protect pathogenic leptospires and allow them to replicate in vivo.

Since the lyophilisation of leptospires presents difficulties, animal passage is used to maintain virulence. Coghlan, Lumsden, and McNeillage (1967) reported the preservation of leptospires at $-79^{\circ} \mathrm{C}$, but did not examine virulence. Alexander et al. (1972) reported the preservation of Leptospira interrogans serotype canicola by the use of liquid nitrogen. Repeated subculture of strains is time consuming, expensive, and may result in loss of virulence (Turner, 1970).

"Polysorbate media" containing polysorbate 80 (Tween 80), albumin, ammonium chloride, thiamine and vitamin $B_{12}$ permit a better study of the nutritional requirements of leptospires than do the traditional media consisting of serum and buffered salt solution (Ellinghausen and McCullough, 1965; Ellinghausen and Sandvik, 1965; Ellinghausen, 1966, 1968a, 1968b).

Polysorbate media were used in this study, the objectives of which were (1) to survey the in-vitro growth patterns of leptospires at $37^{\circ} \mathrm{C}$ and their relationships, if any, to virulence, (2) to examine survival in semisolid medium over extended periods of storage at $23-25^{\circ} \mathrm{C},(3)$ to discover the shelf life of semisolid and liquid medium, and (4) to determine the effect upon leptospiral growth of omitting certain constituents from the medium, or replacing them with other substances. The tests were made with laboratory strains and with leptospires from infected blood, liver, and kidney tissue.

\section{MATERIALS AND METHODS}

Media, diluent and buffer. The standard medium was the basic polysorbate 80 albumin medium described by Ellinghausen and McCullough (1965) and referred to in this paper as P-80 medium. This medium, unmodified or modified, was used in either semisolid or liquid form. Liquid medium was used in 10- $\mathrm{ml}$ volumes in $19 \times 150-\mathrm{mm}$ test tubes closed by $20-\mathrm{mm}$ steel caps. Semisolid medium in $10-\mathrm{ml}$ volumes in $20 \times 125-\mathrm{mm}$ screw-capped

Received 31 Aug. 1972; revised version accepted 19 Feb. 1973.

* Presented at the 2nd International Conference on Wildlife Diseases, Sussex University, 19 July 1971.

J. MED. MICROBIOL.-VOL. 6 (1973)

487 
tubes was prepared with Difco Bacto or BBL (Baltimore Biological Laboratory) Agar. The basal medium without albumin was sterilised as previously described (Ellinghausen and McCullough, 1965). The 5 per cent. albumin (Bovine Serum Albumin Fraction V powder, Miles Laboratory, Kankakee, Illinois) supplement was sterilised by Millipore membrane filtration $(0 \cdot 22 \mu \mathrm{m})$.

One per cent. bovine serum albumin diluent (BSAD) consisted of $1.0 \mathrm{~g}$ of Fraction V powder per $100 \mathrm{ml}$ of 0.005 -M phosphate buffer. The phosphate buffer (PB) contained $87 \mathrm{mg}$ per $1 \mathrm{KH}_{2} \mathrm{PO}_{4}$ and $664 \mathrm{mg}$ per $1 \mathrm{Na}_{2} \mathrm{HPO}_{4}$.

Measurement of leptospiral growth. Growth was measured in liquid culture by means of either a Coleman 7 nephelometer or a Coleman 9 nephelocolorimeter. The medium had a light-transmittance value of 92 per cent. at $400 \mathrm{~nm}$ with a Bausch and Lomb Spectronic 20 colorimeter. The nephelometer was adjusted to zero with uninoculated medium and then calibrated with a Roessler 77.5 turbidity standard (Roessler and Brewer, 1967). Nephelometer readings were related to the total and viable counts in the following manner. Cultures and suspensions adjusted to give a nephelometer reading of 25 were diluted 1 in 10 and counted with a Petroff-Hauser counting chamber. The same adjusted cultures were also diluted decimally from $10^{-1}$ to $10^{-10}$ in BSAD; a 1-ml sample of each dilution was then cultured in $10 \mathrm{ml}$ of semisolid P-80 medium. The correlation between Petroff-Hauser count and viability was routinely verified by this method, within the limits of accuracy imposed by 10 -fold dilutions.

Tests for viability of cultures. Unless stated otherwise, 2 -ml volumes of semisolid cultures stored at $23-25^{\circ} \mathrm{C}$ were carefully inoculated onto the surface of P-80 semisolid medium. Incubation was at $29^{\circ} \mathrm{C}$ until a definite subsurface zone of typical leptospiral growth ("Dinger's zone") appeared. After 90 days, all apparently negative cultures were carefully checked by dark-field microscopy before being discarded. No particular effort was made to protect cultures from the light. In the experiments described it should not be thought that all cultures were tested simultaneously.

Strains of Leptospira. Because all leptospires are now regarded as belonging to a single species, the various organisms in this paper are referred to merely by giving the serotype followed by the strain in parentheses, e.g., pomona (Ohio). Most strains were from the culture collection of this laboratory. The strains used for production of standard antigen had been maintained from 1955 to 1961 by storing in Fletcher's medium at room temperature $\left(23-25^{\circ} \mathrm{C}\right)$ and subculturing at 3-mth intervals. From 1962, P-80 semisolid medium was used and strains were subcultured no more frequently than once every $18 \mathrm{mth}$. The virulent strains mentioned later were all isolated after 1961.

Infected hamsters. Unless otherwise stated, weanling hamsters were given intraperitoneal inoculations of $1 \mathrm{ml}$ of cultures that had reached their maximum turbidity. The cultures so used were at the end of the logarithmic phase of growth and were never older than 7 days. Their viable content was tested by the methods already described.

The MID or MLD for certain strains after periods of storage was determined. The hamsters were killed 14 days after inoculation and blood samples were taken. The kidneys were removed aseptically, placed in $2 \cdot 5-\mathrm{ml}$ sterile disposable syringes and expressed into $10-\mathrm{ml}$ volumes of BSAD. These suspensions were shaken in screw-capped tubes and allowed to settle for $30 \mathrm{~min}$. The tissue suspension supernate was usually then diluted decimally to $10^{-4}$ in BSAD and $1-\mathrm{ml}$ volumes of each dilution were cultured in $10-\mathrm{ml}$ volumes of semisolid P-80 medium.

In one experiment, pomona (MLS)-infected liver (1006 mg) and kidney (645 mg) were directly expressed through the tip of a $2 \cdot 5-\mathrm{ml}$ syringe into $10 \mathrm{ml}$ of P-80 semisolid medium.

Microscopic agglutination $(M A)$ test. Equal volumes of homologous antigen suspension were added to dilutions of hamster serum, the maximum final serum dilution being $10^{-6}$. The antigen suspensions had a light transmittance of 57-63 per cent. Bacterial dry weights of antigen suspensions ranged from 50-68 $\mu \mathrm{g}$ per $\mathrm{ml}$; these were determined by subjecting concentrated antigen suspensions to carefully controlled drying at $100^{\circ} \mathrm{C} \pm 1.0^{\circ}$ for $24 \mathrm{hr}$. Cell counts averaged $200 \times 10^{6}$ cells per $\mathrm{ml}$, but there was no uniform correlation amongst strains between cell count and turbidity. An incubation time of $1 \mathrm{hr}$ at $25^{\circ} \mathrm{C}$ was used for the MA test. 
Porcine blood infected with pomona (HCE). Citrated blood from a pig contained the strain in its twelfth serial passage. The blood was cultured in various media, the inocula being $0 \cdot 3-\mathrm{ml}$ volumes of decimal dilutions from $10^{-1}$ to $10^{-8}$, prepared in BSAD.

\section{RESULTS \\ Continuous subculture of leptospiral strains at $37^{\circ} \mathrm{C}$, and inoculation of hamsters}

Strains were tested for their ability to grow continuously at $37^{\circ} \mathrm{C}$ on repeated subculture at 7-day intervals in liquid P-80 medium from 1-ml inocula. Growth was measured nephelometrically, and viability at the end of the first subculture was tested by inoculating liquid P-80 medium and incubating at $29^{\circ} \mathrm{C}$; viability at the end of the second subculture was tested similarly, except that semisolid P- 80 medium was used. Of 27 strains, 23 were virulent or avirulent pathogens; four strains were saprophytes, namely illini $(3055 \mathrm{H})$, biflexa (SC3), biflexa (Patoc 1), and biflexa (CDC). The results are shown in table I.

All except two of the 23 pathogenic strains and two of the four saprophytic strains were viable at the end of the first subculture. By the end of the second subculture a further nine pathogenic strains had shown greatly reduced growth as estimated by turbidity measurements and they were no longer viable.

Table I depicts three main types of leptospiral growth pattern at $37^{\circ} \mathrm{C}$. Some strains, e.g., pomona (HCE) rapidly died with no evidence of multiplication. Others, e.g., pomona (3341), showed depressed growth at the second subculture, with subsequent recovery. Still others, e.g., illini $(3055-\mathrm{H})$ showed growth that was both continuous and vigorous. The pattern of growth amongst a number of pomona strains was quite variable, while all grippotyphosa strains were uniformly susceptible to growth inhibition at $37^{\circ} \mathrm{C}$.

Serotype pomona (Ohio) grew well at $37^{\circ} \mathrm{C}$, but a human isolate, pomona (HCE), considered to have been derived from pomona (Ohio) through an accidental infection, no longer had the ability to grow at $37^{\circ} \mathrm{C}$.

Hamsters were inoculated with the 27 strains, 25 of which had been maintained in semisolid P-80 medium at $25^{\circ} \mathrm{C}$ and before inoculation were subcultured at $29^{\circ} \mathrm{C}$ three times at 7-day intervals in liquid medium, while illini (3055-H) and biflexa (SC3) had been grown continuously at $37^{\circ} \mathrm{C}$.

Table I gives an indication of virulence as shown by the ability of the strains to infect the kidney, and by antibody response. Virulence could not be correlated with the ability to grow in vitro at $37^{\circ} \mathrm{C}$.

\section{Survival and virulence after storage in semisolid medium}

Twenty-nine strains were tested; most of these strains have already been named in table I. Two millilitres of culture of each strain were inoculated into $10 \mathrm{ml}$ of semisolid P-80 medium. Tubes were incubated at $29^{\circ} \mathrm{C}$ until growth appeared and they were then stored at $23-25^{\circ} \mathrm{C}$. Viability tests were carried out at intervals.

All strains were viable $12 \mathrm{mth}$ later, and of 28 strains tested after $18 \mathrm{mth}$ storage only one, grippotyphosa (B-697), was non-viable. After $24 \mathrm{mth}$, each 
of 21 strains was viable. Examination of a small number of cultures at a later date suggested that even more prolonged survival occurred; for example, pomona (strains $\mathrm{DM}_{2} \mathrm{H}$, and $\mathrm{JB}$ ) were viable after $36 \mathrm{mth}$, and pomona (HCE) after $52 \mathrm{mth}$.

TABLE I

Lack of correlation between ability of leptospires to grow in continuous subculture at $37^{\circ} \mathrm{C}$ and virulence

\begin{tabular}{|c|c|c|c|c|c|c|c|c|}
\hline \multirow{2}{*}{ Serotype and strain } & \multicolumn{6}{|c|}{$\begin{array}{c}\text { Nephelometer readings of } \\
\text { subculture numbers }\end{array}$} & \multicolumn{2}{|c|}{$\begin{array}{c}\text { Results of } \\
\text { hamster inoculation }\end{array}$} \\
\hline & 1 & su & . & sum & 5 & 6 & $\begin{array}{l}\text { Kidney } \\
\text { infected }\end{array}$ & $\begin{array}{l}\text { Reciprocal } \\
\text { MA titre }\end{array}$ \\
\hline $\begin{array}{l}\text { pomona (HCE) } \\
\text { pomona (Ohio) } \\
\text { pomona (MLS) } \\
\text { pyrogenes (Salinem) } \\
\text { autumnalis (Akiyami A) } \\
\text { grippotyphosa (Moskva V) } \\
\text { grippotyphosa (B-697) } \\
\text { grippotyphosa (B-699) } \\
\text { grippotyphosa (ICS) } \\
\text { tarassovi (Perepelicin) } \\
\text { georgia (LT-117) } \\
\left.\text { pomona (DM }{ }_{2} \mathrm{H}\right) \\
\text { pomona (JB) } \\
\text { pomona (3341) } \\
\text { pomona (T-262) } \\
\text { copenhageni (Wijnberg) } \\
\text { copenhageni (M-20) } \\
\text { canicola (Ruebush) } \\
\text { canicola (Hond Utrecht IV) } \\
\text { ballum (S-102) } \\
\text { australis (Ballico) } \\
\text { wolffi (3705) } \\
\text { hardjo (WR) } \\
\text { illini (3055-H) } \\
\text { biflexa (SC 3) } \\
\text { biflexa (Patoc 1) } \\
\text { bifiexa (CDC) }\end{array}$ & $\begin{array}{l}23 \\
35 \\
28 \\
18 \\
11^{*} \\
20 \\
40 \\
41^{*} \\
29 \\
17 \\
22 \\
32 \\
22 \\
32 \\
38 \\
26 \\
21 \\
20 \\
29 \\
24 \\
24 \\
32 \\
31 \\
80 \\
60 \\
20^{*} \\
4^{*}\end{array}$ & $\begin{array}{c}2^{*} \\
27 \\
1^{*} \\
1^{*} \\
1^{*} \\
1^{*} \\
1^{*} \\
1^{*} \\
5^{*} \\
1^{*} \\
28 \\
13 \\
7 \\
16 \\
12 \\
6 \\
26 \\
26 \\
8^{*} \\
14 \\
25 \\
35 \\
80 \\
60 \\
0^{*} \\
0^{*}\end{array}$ & $\begin{array}{r}1 \\
35 \\
1 \\
1 \\
1 \\
1 \\
1 \\
1 \\
1 \\
1 \\
1 \\
43 \\
21 \\
20 \\
34 \\
21 \\
25 \\
20 \\
25 \\
0 \\
24 \\
31 \\
28 \\
80 \\
60 \\
0 \\
0\end{array}$ & $\begin{array}{r}0 \\
34 \\
1 \\
0 \\
0 \\
0 \\
0 \\
0 \\
0 \\
0 \\
0 \\
36 \\
22 \\
22 \\
27 \\
8 \\
29 \\
2 \\
30 \\
0 \\
0 \\
33 \\
36 \\
80 \\
60 \\
0 \\
0\end{array}$ & $\begin{array}{r}0 \\
35 \\
0 \\
0 \\
0 \\
0 \\
0 \\
0 \\
0 \\
0 \\
0 \\
22 \\
19 \\
19 \\
27 \\
28 \\
10 \\
0 \\
23 \\
0 \\
0 \\
23 \\
25 \\
80 \\
60 \\
0 \\
0\end{array}$ & $\begin{array}{r}0 \\
40 \\
0 \\
0 \\
0 \\
0 \\
0 \\
0 \\
0 \\
0 \\
0 \\
40 \\
40 \\
25 \\
40 \\
28 \\
29 \\
0 \\
30 \\
0 \\
0 \\
35 \\
42 \\
80 \\
60 \\
0 \\
0\end{array}$ & $\begin{array}{l}++ \\
+ \\
\pm \\
= \\
= \\
= \\
\pm \\
\pm \\
= \\
\pm \\
\pm \\
= \\
= \\
= \\
= \\
= \\
= \\
= \\
= \\
= \\
=\end{array}$ & $\begin{array}{r}10,000 \\
1,000 \\
100 \\
10 \\
10 \\
10 \\
10 \\
1,000 \\
10 \\
10 \\
100 \\
10,000 \\
100 \\
10 \\
10 \\
10 \\
10,000 \\
10 \\
10 \\
100 \\
1,000 \\
100 \\
10,000 \\
1,000 \\
100 \\
10\end{array}$ \\
\hline
\end{tabular}

* = Subculture non-viable after 7 days' incubation.

$\dagger=$ Hamsters died.

MA = Microscopic agglutination test.

Survivors killed and serum samples taken 14 days after inoculation.

After storage for $52 \mathrm{mth}$, pomona (HCE) was cultured for 7 days at $29^{\circ} \mathrm{C}$ in liquid medium and inoculated into groups of four hamsters in decimal dilutions ranging from $2 \times 10^{8}$ to 20 organisms. All the animals died.

After storage for $7 \mathrm{mth}$, pomona (Ohio) was similarly tested in pairs of hamsters. Doses of $3 \cdot 12 \times 10^{8}$ and $3.12 \times 10^{7}$ each caused the death of one of a pair of hamsters within 8 days. No deaths occurred in pairs of animals inoculated with $3 \cdot 12 \times 10^{6}, 3 \cdot 12 \times 10^{5}$, and $3 \cdot 12 \times 10^{4}$ cells, but when killed 26 days after inoculation each hamster had renal infection as shown by culture of a $10^{-4}$ dilution of kidney tissue suspension. 
After 24 serial subcultures of 7 months' total duration in liquid medium at $29^{\circ} \mathrm{C}$, pomona (Ohio) failed to cause death in pairs of hamsters inoculated with decimal-dose dilutions ranging from $1.36 \times 10^{8}$ to $1.36 \times 10^{4}$ leptospires, but cultures of $10^{-4}$ dilutions of kidney tissue suspensions at necropsy, 26 days after inoculation, invariably gave positive results. MA titers of $10^{5}$ were found in all but two hamsters inoculated with $1.36 \times 10^{7}$ to $1.36 \times 10^{5}$ cells and killed 26 days later. The two hamsters inoculated with $1.36 \times 10^{4}$ cells had MA titers of $10^{4}$.

\section{Keeping qualities of semisolid and liquid $P-80$ medium}

Semisolid P-80 medium stored for $36 \mathrm{mth}$ at $23-25^{\circ} \mathrm{C}$ supported growth of small numbers of pomona $\left(\mathrm{DM}_{2} \mathrm{H}\right)$. Macroscopic growth was invariably visible after 3 days' incubation at $29^{\circ} \mathrm{C}$ in tubes inoculated with $2.2 \times 10^{7}$ cells. When the inoculum was reduced to $2.2 \times 10^{6}, 2.2 \times 10^{5}$, and $2.2 \times 10^{4}$ cells, growth was visible at 6-9, 7-13, and 13-16 days respectively, except for the 36-month-old medium inoculated with $2.2 \times 10^{4}$ cells. In this tube a Dinger's zone did not appear, but darkfield examination after 24 days' incubation showed living organisms, and subculture in 3-month-old semisolid P-80 medium produced growth that was macroscopically detectable after $72 \mathrm{hr}$.

Liquid P-80 medium stored for $12 \mathrm{mth}$ at $23-25^{\circ} \mathrm{C}$ was also tested with pomona $\left(\mathrm{DM}_{2} \mathrm{H}\right)$. Decimal dilutions containing $22.6 \times 10^{6}$ to 2 organisms per $\mathrm{ml}$ were prepared in tubes containing $10 \mathrm{ml}$ medium. After 21 days' incubation, the nephelometer readings of the eight tubes were, respectively, $48,58,60,51$, $51,30,5$, and 0 . After 28 days' incubation the corresponding readings were $48,49,52,59,58,52,54$, and 54 .

\section{Survival of leptospires in BSAD}

A suspension of illini $(3055 \mathrm{H})$, a robust organism, was washed twice in sterile PB and diluted decimally to extinction in BSAD. After the tubes had been held at $23-25^{\circ} \mathrm{C}$ for four days, viability was checked. Diluent which originally contained $2.46 \times 10^{8}$ to $2.46 \times 10^{5}$ cells per ml yielded viable organisms, but that originally containing $2.46 \times 10^{4}$ cells per ml or less was sterile. After 30 and 340 days' storage only those suspensions originally containing $2.46 \times 10^{8}$ and $2.46 \times 10^{7}$ cells per $\mathrm{ml}$ were viable. After 510 days' storage, suspensions originally containing $2.46 \times 10^{7}$ cells per $\mathrm{ml}$ were still viable.

Fourteen further strains or variants were similarly tested for their viability in BSAD, and also in PB, after storage for 7 days at $23-25^{\circ} \mathrm{C}$. The results, shown in table II, demonstrated the superiority of BSAD.

In a similar experiment, nine other strains remained viable for at least 51 days in BSAD and PB when the original counts were high $\left(30.8 \times 10^{6}\right.$ to $20 \times 10^{6}$ cells per $\mathrm{ml}$ ); the strains tested were copenhageni (M-20), javanica (Veldrat Batavia 46), canicola (strains Hond Utrecht IV, NADL-A13, and Moulton), ballum (S-102), pyrogenes (Salinem), pomona (HCE), and ranae (ICF).

Recent tests with pomona $\left(\mathrm{DM}_{2} \mathrm{H}\right.$ and JB) and illini $(3055 \mathrm{H})$ have shown that suspensions originally containing approximately $2 \times 10^{7}$ cells per ml BSAD were still viable after $17 \mathrm{mth}$ at $23-25^{\circ} \mathrm{C}$. Serotype pomona (JB) was still capable 


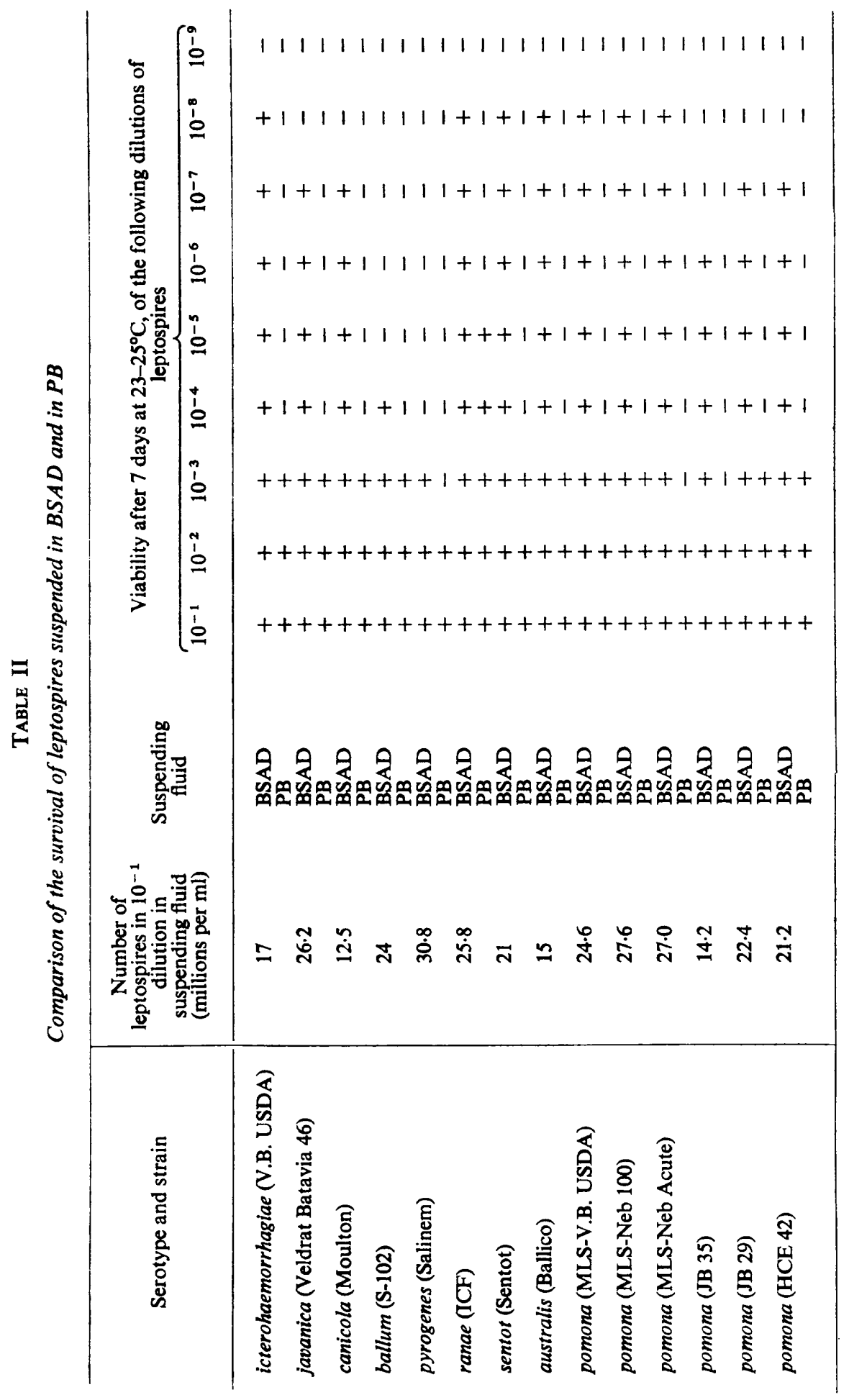


of infecting hamsters; although death did not occur, isolations were made from blood, liver, and kidney at necropsy of the hamsters 28 days after inoculation.

\section{Culture of infected blood in modified or incomplete forms of $P-80$ medium}

A comparison was made of the growth-supporting properties of the semisolid P-80 medium and the following modified forms: standard medium without polysorbate 80 ; three media in which polysorbate 80 was replaced by either polysorbate 60,40 or 20 ; three media in which either $\mathrm{NH}_{4} \mathrm{Cl}$, thiamine or vitamin $B_{12}$ was omitted. When the 8 media were inoculated with $0 \cdot 3-\mathrm{ml}$ volumes of decimal dilutions of blood from a pig infected with pomona (HCE) the limiting dilutions of blood for growth in these media were shown to be $10^{-6}, 10^{-3}, 10^{-6}, 10^{-7}, 10^{-6}, 10^{-5}, 10^{-5}$, and $10^{-3}$ respectively. Growth was assessed visually at intervals from the 10th to 90 th day of incubation at $29^{\circ} \mathrm{C}$. Thus, the omission from the standard medium of either its polysorbate or vitamin $B_{12}$ content had a strikingly adverse effect on growth.

The possibility of continuous subculture at $29^{\circ} \mathrm{C}$ was also examined in relation to the eight media. Cultures from limiting dilutions of blood in each of the eight media were subcultured at 7-day intervals in the parent media. Continuous serial propagation in media lacking either polysorbate, $\mathrm{NH}_{4} \mathrm{Cl}$ or thiamine did not give well-formed Dinger's zones and therefore growth was not readily detectable; a low level of growth did take place but was demonstrable only by subculture in complete semisolid P-80 medium. Continuous subculture with clear Dinger's zones proved possible in each of the four complete polysorbate media (P-80, P-60, P-40, P-20) and also, surprisingly, in medium lacking vitamin $\mathrm{B}_{12}$.

Similar tests were made with eight comparable liquid media. When the inoculum was a $10^{-2}$ dilution of the infected blood, growth became visible after 10-12 days' incubation in all media, except that deficient in polysorbate; in this medium growth did not appear until the 17th day of incubation. Growth from a $10^{-6}$ dilution of blood took place in media lacking $\mathrm{NH}_{4} \mathrm{Cl}$ or thiamine. In vitamin $B_{12}$-deleted medium macroscopically-detectable growth did not occur from dilutions of blood greater than $10^{-2}$, but continuous subculture in the parent medium was successful.

\section{Survival of pomona (HCE) in primary cultures made from porcine blood}

Use was made of the positive cultures in semisolid media from limiting dilutions of blood in the previous experiment.

Cultures in the four polysorbate media and the polysorbate-deficient medium were stored for 7 months at $23-25^{\circ} \mathrm{C}$ and then tested for viability. All were viable and, moreover, each grew with a Dinger's zone when transferred to its parent medium, except for the culture in polysorbate-deficient medium. In the latter, heavy growth as indicated by an obvious Dinger's zone did not develop but, probably because of the albumin content of the medium, viable organisms were present and could be detected by darkfield examination or subculture on complete media. Cultures from limiting dilutions of blood in the three media 
deficient in $\mathrm{NH}_{4} \mathrm{Cl}$, thiamine or vitamin $\mathrm{B}_{12}$ were subcultured from one to three times in the parent media. Again, the final subcultures survived storage for $7 \mathrm{mth}$ at $23-25^{\circ} \mathrm{C}$.

\section{Survival of 10 strains in modified or incomplete forms of P-80 semisolid medium}

The following strains or variants were tested: pomona $\left(\mathrm{DM}_{2} \mathrm{H}\right.$ and JB), grippotyphosa (Moskva V; Racoon, Ga.; Bobcat, Ga.; Squirrel, ICS; Swamp Rabbit, Ga.; Cottontail Rabbit, Ga.), illini (3055 hooked), and illini (3055 nonhooked). Approximately $2 \times 10^{6}$ viable organisms of each strain were inoculated into semisolid P-80 medium and into the seven modified or incomplete forms of P-80 medium already described. The eighty inoculated cultures were incubated at $29^{\circ} \mathrm{C}$ until growth appeared, and stored for $18 \mathrm{mth}$ at $23-25^{\circ} \mathrm{C}$. Subcultures in P-80 medium made to examine survival gave obvious Dinger's zones of growth within 30 days in all except three instances. The subcultures of the two varieties of illini (3055) stored in the eight different media gave visible growth simultaneously. There was some variation between the other subcultures in the experiment in respect of the time of first appearance of growth, but this seemed to be of a random nature and could not be related to strain differences or to differences between the eight media used. Two cultures required repeated sampling to show viability, and 79 recoveries were finally made from the 80 cultures.

\section{Isolation of pomona (MLS) from liver and kidney tissue in complete or vitamin $B_{12}$-deficient medium}

Semisolid P-80 medium, with and without vitamin $B_{12}$, was used in attempting isolations of pomona (MLS) from the liver and kidney tissue of hamsters infected four days earlier by intraperitoneal inoculations of a $10^{-4}$ dilution of liver tissue from a dying hamster.

The organism could be isolated from $0.1 \mathrm{mg}$ of hamster-liver tissue, prepared by a dilution technique, regardless of the presence of vitamin $B_{12}$. Continuous serial subculture at 14-day intervals was possible in complete and $\mathrm{B}_{12}$-deficient medium. Eleven months after original isolation the primary cultures, with or without vitamin $\mathrm{B}_{12}$ and kept at $23-25^{\circ} \mathrm{C}$ were still viable.

A $10^{-4}$ dilution of kidney tissue $(0.006 \mathrm{mg})$ gave leptospiral growth in complete P-80 medium, but not in vitamin $\mathrm{B}_{12}$-deficient medium.

Kidney tissue was also cultured in liquid P-80 medium, in which growth could be more readily quantitated. Culture of $0.64 \mathrm{mg}$ of kidney tissue in vitamin $B_{12}$-deficient medium had, after 7 days' incubation, a nephelometer reading of 6 , while in the complete medium the value was 42 . These two cultures were subcultured in parent liquid medium and after three days the nephelometer readings were 0 and 28 respectively. With an additional four days' incubation the turbidity value was still 0 in non-supplemented medium and no further subculture was possible. By contrast, the nephelometer reading of the culture in complete medium had risen to 45 , and continuous subculture producing heavy growth was possible. 


\section{Discussion}

No correlation between virulence and the ability of leptospires to grow continuously and well at $37^{\circ} \mathrm{C}$ in vitro was established. The three patterns of growth seen at $37^{\circ} \mathrm{C}$ indicate that different cultural populations occur. Serological classification does not necessarily correspond with temperature sensitivity: two biflexa strains were very heat sensitive whilst another strain grew well at $37^{\circ} \mathrm{C}$.

Serotype pomona (Ohio) grew well at $37^{\circ} \mathrm{C}$, but upon re-isolation as pomona (HCE) from an accidental human infection, it could no longer grow at this temperature. On the other hand, pomona $\left(\mathrm{DM}_{2} \mathrm{H}\right)$ was capable of growth at $37^{\circ} \mathrm{C}$ both before and after passage through a human host.

Pasteurella pestis was found to be avirulent when cultured at $5^{\circ} \mathrm{C}$ (Panos and Ajl, 1963), but was virulent when grown at $37^{\circ} \mathrm{C}$. The respiration of a leptospiral isolate from frog kidney (Ellinghausen, 1968b) diminished drastically when it was grown at $32.5^{\circ} \mathrm{C}$ instead of $29^{\circ} \mathrm{C}$. Steinberg, Horswood, and Chanock (1969) attempted to obtain temperature-sensitive mutants of Mycoplasma pneumoniae in the hope that they would prove immunogenic against respiratory disease. Such approaches should be considered in relation to leptospiral diseases.

Manew (1969) reported that only two out of 138 leptospiral strains survived six months' storage in Fletcher's medium. The present study indicates that yearly subcultures in P-80 semisolid medium are likely to be satisfactory. The improved survival of leptospires in BSAD as compared with that in PB supports the finding of Schubert and Sulzer (1970) who noted the value of 6 per cent. bovine albumin in the preservation of leptospires.

The chemical contaminants in bovine albumin (Hanson and Ballard, 1968) such as fatty acids, citrate, lactate, pyruvate, aspartate, and alpha-keto-glutarate might account for its preserving activity. Chen (1967) used charcoal treatment to remove fatty acids from albumin, but albumin so treated was shown to be an inferior component of P-80 medium when tested with many strains of leptospires (Ellinghausen, unpublished data). Only by the use of minimal inocula can the value of albumin purified in different ways be assessed. Whether purification processes affect the ability of albumin to bind long-chain fatty acids or whether they remove traces of growth-stimulating substances is not known.

Leptospires stored for long periods in P-80 semisolid medium retained virulence, and one strain, pomona (HCE), was still lethal for hamsters in a dose of 20 organisms after storage for $52 \mathrm{mth}$. Semisolid P-80 medium was shown to have a shelf-life of at least $36 \mathrm{mth}$ and this is probably significant in relation to the ability of the medium to preserve the viability of leptospires for long periods. No evidence of lipase activity in bovine albumin has been found (Ellinghausen and Sandvik, 1965) and this fact makes breakdown of the medium less likely. The long shelf-life of P-80 medium, both liquid and semisolid, is also of value in that it permits thorough testing of the quality of each batch before use. 
Pearce and Lowrie (1972) have reviewed the possible mechanisms of localisation of bacteria in certain host tissues, paying due attention to nutritional factors which limit growth. The present paper includes studies on the general nutrition of virulent leptospiral isolates. The role of supplementary growth lipid in the form of polysorbate was immediately obvious, but one or two additional subcultures were necessary in medium lacking $\mathrm{NH}_{4} \mathrm{Cl}$ or thiamine before the importance of these nutrients for maximum growth became apparent.

That growth can occur in P-80 medium from which certain nutrients are omitted suggests that the albumin component plays a vital role. Nutrientdeleted media could well provide an environment where growth is minimised, and this might be especially favourable for preservation of viability and virulence.

It was shown that pomona (MLS) isolated from liver had different vitamin $B_{12}$ requirements from those of the same organism isolated from kidney. Differences in lipid requirements of leptospires isolated from brain, blood, kidney, liver, and urine await further study. Such a study may depend on further refinements in the purification of albumin.

The temperatures required by different isolates for maximum growth and virulence are still unpredictable. Advances have been made in understanding of the nutritional and metabolic requirements of leptospires, but how the latter affect leptospiral infections is unknown. Factors which permit the survival and multiplication of leptospires in vivo require deeper scrutiny.

\section{SUMMARY}

Some virulent and avirulent pathogenic leptospires and saprophytic leptospires grew continuously at $37^{\circ} \mathrm{C}$, while others did not; variations amongst strains of the same serotype occurred and there was no correlation with virulence.

Each of 21 strains survived 24 months' storage in semisolid polysorbate medium (P-80 medium) without intervening subculture and one strain tested after 52 months was still viable and fully virulent. Semisolid and liquid P-80 media had a shelf-life of at least 36 and 12 months respectively at $23-25^{\circ} \mathrm{C}$.

One per cent. albumin was shown to favour the survival of leptospires.

In experiments with modified or incomplete semisolid P-80 medium, various leptospiral strains grew and survived when polysorbate, 60,40 , or 20 were substituted for polysorbate 80 , and when polysorbate, $\mathrm{NH}_{4} \mathrm{Cl}$, thiamine, or vita$\min B_{12}$ were omitted. However, the omission of any polysorbate or of vitamin $B_{12}$ had a strikingly adverse effect on growth. These modified media were used to culture blood infected with pomona (HCE). Continuous subculture eventually failed to produce readily-detectable macroscopic growth in the absence of either polysorbate, $\mathrm{NH}_{4} \mathrm{Cl}$ or thiamine, but continuous subculture in the absence of vitamin $B_{12}$ was successful. Nutrient-depleted P-80 media were still capable of maintaining viability and a low level of growth, probably because of the micronutrients in the one per cent. albumin component. Continuous subculture of pomona (MLS) from hamster liver was successful regardless of the presence of vitamin $B_{12}$ in the medium, but vitamin $B_{12}$ was essential for similar subculture of the same organism isolated from kidney. 


\section{REFERENCES}

Alexander, A. D., Lessel, E. F., Evans, L. B., Franck, E., AND Green, S. S. 1972. Preservation of leptospiras by liquid-nitrogen refrigeration. Int. J. Syst. Bact., 22, 165.

ChEN, R. F. 1967. Removal of fatty acids from serum albumin by charcoal treatment. J. Biol. Chem., $242,173$.

Coghlan, Joyce D., Lumsden, W. H. R., AND McNeillage, G. J. 1967. Low temperature preservation of Leptospira, preliminary communication. J. Hyg., Camb., 65, 373.

Ellinghausen, H. C., JR 1966. The effect of aeration upon the growth of Leptospira serotypes. Am. J. Vet. Res., 27, 975.

Ellinghausen, H. C., JR 1968a. Stimulation of leptospiral growth by glucose. Am. J. Vet. Res., 29, 191.

EllinghaUSEN, H. C., JR 1968b. Cultural and biochemical characteristics of a leptospire from frog kidney. Bull. Wildlife Dis. Ass., 4, 41.

Ellinghausen, H. C., JR, AND MCCullough, W. G. 1965. Nutrition of Leptospira pomona and growth of 13 other serotypes: fractionation of oleic albumin complex and a medium of bovine albumin and polysorbate 80. Am. J. Vet. Res., 26, 45.

Ellinghausen, H. C., JR, AND SANDVIK, O. 1965. Tributyrinase activity of leptospires: fixed and soluble tributyrinase demonstrated by means of an agar diffusion test. Acta. path. microbiol. scand., 65, 259.

HaNson, R. W., AND Ballard, F. J. 1968. Citrate, pyruvate, and lactate contaminants of commercial serum albumin. J. Lipid Res., 9, 667.

MANEW, C. 1969. A double-layer nutrient medium for the maintenance of leptospira strains. Zentbl. Bakt. ParasitKde, I Abt. Orig., 210, 216 (in German).

Panos, C., AND AJl, S. J. 1963. Metabolism of microorganisms as related to their pathogenicity. A. Rev. Microbiol., 17, 297.

PearCe, J. H., AND LoWrIE, D. B. 1972. Tissue and host specificity in bacterial infection. In Microbial pathogenicity in man and animals, 22nd Symp. Soc. Gen. Microbiol., 1972, London, p. 193.

Roessler, W. G., AND Brewer, C. R. 1967. Permanent turbidity standards. Appl. Microbiol., 15, 1114.

Schubert, J. H., AND Sulzer, Catherine 1970. Preservation of Leptospira by storage at $-75^{\circ} \mathrm{C}$ versus transferring every three months. Bact. Proceed., $20,20$.

Steinberg, P., Horswood, R. L., AND ChanOCK, R. M. 1969. Temperature-sensitive mutants of Mycoplasma pneumoniae. I. In-vitro biologic properties. J. Infect. Dis., 120, 217.

TURNER, L. H. 1970. Leptospirosis III. Maintenance, isolation, and demonstration of leptospires. Trans. R. Soc. Trop. Med. Hyg., 64, 623. 